\title{
Prevalence of injury and associated factors among patients visiting the Emergency Departments of Amhara Regional State Referral Hospitals, Ethiopia: a cross-sectional study
}

\author{
Debrework Tesgera Bashah', Berihun Assefa Dachew ${ }^{2 *}$ and Bewket Tadesse Tiruneh ${ }^{1}$
}

\begin{abstract}
Background: Injury significantly affecting the health and well-being of the society.

The prevalence tends to be higher in low income countries. The aim of this study was to assess the prevalence of injury and associated factors among patients visiting emergency departments of Amhara Regional State referral hospitals.

Methods: Institution based cross sectional study was conducted from March to April 2014. The systematic random sampling technique was employed to select the study participants. The data were collected using an interviewer administered questionnaire. Bivariate and multivariate logistic regressions were performed to identify factors associated with injury. Odds ratios with $95 \%$ confidence interval were computed to determine the level of significance.

Result: The prevalence of injury was $55.6 \%$. Being male ( $A O R=2.8 ; 95 \% \mathrm{Cl}, 1.79-4.47)$, monthly income less than 34.2 USD (AOR = 1.89; $95 \% \mathrm{Cl}, 1.03-3.46)$, being age between 20 to 44 years ( $\mathrm{AOR}=2.25 ; 95 \% \mathrm{Cl}, 1.06-4.81$ ), being a daily laborer ( $A O R=6.27 ; 95 \% \mathrm{Cl}, 2.38-16.47$ ), being a farmer ( $\mathrm{AOR}=2.9 ; 95 \% \mathrm{Cl}, 1.31-6.41$ ) and being a substance user $(A O R=2.16 ; 95 \% \mathrm{Cl}, 1.18-3.96)$ were significantly associated with injury.

Conclusion: The prevalence of injury was high. Being male, age 20 to 44 years, income $<34.2$ USD, being a daily laborer, being a farmer and alcohol use were factors associated with injury. Hence, appropriate injury prevention strategy should be designed in order to lessen the magnitude of injury.
\end{abstract}

\section{Background}

Injury has profound impact on the individual and the entire society. It is becoming one of the leading causes of premature death and disability. It contributes to $16 \%$ of the global burden of disease and $10 \%$ of mortality [1-3]. The burden of injury is highest between the ages of 15 and 45 years [4-6]. This age group is believed to be the most productive, and injury will in turn have an impact on growth and economic development of a nation.

\footnotetext{
* Correspondence: berihunassefa21@gmail.com

${ }^{2}$ Department of Epidemiology and Biostatistics, Institute of Public Health, College of Medicine and Health Sciences, University of Gondar, Gondar, Northwest Ethiopia

Full list of author information is available at the end of the article
}

According to World Health Organization (WHO), low and middle income countries (LMICs) share more than $90 \%$ of injury cases. Of which Africa regions contribute for about $21 \%$, mainly the sub Saharan countries [3]. Reports from South Africa and Zimbabwe revealed that injury accounted for the largest proportion of all deaths and morbidities [7]. Findings from East Africa countries such as Kenya, Sudan and Tanzania demonstrate that there is a significant growing burden of traumatic injuries $[2,8]$.

In Ethiopia, like other developing countries, injury is a common public health problem [9]. Research conducted at university of Gondar referral hospital revealed that injury accounts for $25 \%$ of surgical cases [10].

Although injuries are known to be preventable, still it continues to be the a widespread health problem [3, 4]. 
In Ethiopia, despite government efforts to reduce road traffic injuries, injury is increasing at an alarming rate and constitute around half of all surgical emergencies [11, 12]. On the other hand, lack of sufficient data about its magnitude leads to underestimation of injury burden [13]. Thus to design effective prevention strategies, there is need of findings about the magnitude of injury and its associated factors. Therefore, the aim of this study was to determine the magnitude of injury and its associated factors among patients visiting the emergency departments of Amhara regional 74 state referral hospitals, Ethiopia.

\section{Methods}

An institution based cross-sectional study was conducted from March to April 2014 in Amhara national regional state referral hospitals. Amhara national regional state is one of the federal republic of Ethiopia regional states, with an estimated area of 159,173.66 square kilometers. Based on the Central Statistical Agency (CSA) of Ethiopia 2007, the region has an estimated total population of 20,136,000, consisting of 10,060,000 men and 10,076,000 women. Eighty eight percent of the population is estimated to be rural inhabitant, while $12 \%$ are urban dwellers. Health and health related indicators published by the federal ministry of health $(\mathrm{FMoH})$ reveals that, there are 20 hospitals, including the five referral hospitals in the region [14].

In this study all patients who visited the emergency departments of the three referral hospitals of Amhara regional state (both injured and non-injured) were included in the study. Whereas those patients who were seriously ill and in need of urgent transfers to another health institution were excluded. Injury cases were operationally defined as patients who encountered sustained physical trauma prior to appearing to the emergency department of the referral hospitals.

The sample was calculated using single population proportion formula to obtain the sample size needed to estimate the prevalence of injury in the population visiting referral hospitals of Amhara regional state. It was determined by the assumptions of $95 \%$ confidence level, $4 \%$ margin of error, and taking the prevalence of injury $8.2 \%$ [15]. Taking into account design effect of two and considering $15 \%$ non response rate, the final simple size became 416. Among five referral hospitals in Amhara region (Dessie, Debre-99 Birhan, Debre-Markos, FelegeHiwot and university of Gondar hospital) three referral hospitals namely Debre-Birhan hospital, Felege-Hiwot hospital and University of Gondar hospital were taken by a lottery method. The participants were included proportionally by considering the daily patient flow of emergency departments of the selected referral hospitals; that is participants from University of Gondar Hospital, 137 from Felege-Hiwot hospital and 122 participants from Debre-Birhan hospital. Then systematic sampling technique was used to select study participants and every third patient was selected until the desired sample size was obtained.

Semi-structured questionnaire adapted from WHO injury surveillance document was used to collect the data. The tool was validated in low and middle income countries. It was modified to fit the study population. Pretest was conducted to check compatibility of the tool. The questionnaire was first prepared in English and then translated into the local language (Amharic), and back to English to ensure consistency. This questionnaire gathered data on injury events, nature, severity and patient disposition. Field supervisors reviewed the questionnaires daily.

Data cleaning was carried out by the principal investigator. Data were checked for completeness, coded and entered to Epi-info version 3.5.1 statistical software and was exported to SPSS (Statistical Package for Social science) windows version 20 for further analysis. Frequencies and cross tabulations were used to summarize descriptive statistics of the data. Bivariate logistic analysis was used primarily to check variables which have associations with the dependent variable. Variables found to have associated with the dependent variable at $\mathrm{p}$-value $<0.02$ were then entered into multiple logistic regression for controlling the possible effect of confounders and finally the variables with significant association at $\mathrm{P}$-value $<0.05$ were identified 124 on the basis of Odds Ratio with $95 \%$ confidence interval.

Ethical clearance was obtained from Ethical review committee of University of Gondar (Reference Number 1038/06) and permission was secured from the head offices of the respective referral hospitals with a formal letter of cooperation. Each respondent was informed about the purpose of the study and informed verbal consent was obtained from each study participants before the actual data collection.

\section{Results}

Socio demographic characteristics of study participants

Among the 416 study participants, 414 responded to the interview making the response rate of $99 \%$. In this study, males outnumbered females by a sex ratio of 2: 1 , (males $278(67.1 \%)$ and females 136 (32.9 \%). The mean and SD of age of patients was $30( \pm 16)$ years. Majority $356(86 \%)$ of the study participants were Orthodox Christian. Regarding the marital status, 219 (53\%) of the participants were single. Among the participants 229 (55.3\%) were urban dwellers. The data about the educational level of the study subjects' showed that 198 (47.8\%) have no formal education and 109 (26.3 \%) have attended primary education. Among the 414 patients consented to interview, 98 (23.7 \%) have monthly income less than 34.2 USD, and a similar proportion of the group had income ranging between 34.3 -73.4 USD (Table 1). 
Table 1 Socio-demographic characteristics of the study participants visiting emergency departments (EDs) of Amhara regional state referral hospitals, 2014; $(n=414)$

\begin{tabular}{|c|c|c|}
\hline Variables & Frequency, $n=414$ & Percent \\
\hline \multicolumn{3}{|l|}{ Sex } \\
\hline Male & 278 & 67.1 \\
\hline Female & 136 & 32.9 \\
\hline \multicolumn{3}{|l|}{ Age in years } \\
\hline$<4$ & 19 & 4.6 \\
\hline $5-14$ & 45 & 10.9 \\
\hline $15-19$ & 38 & 9.2 \\
\hline $20-24$ & 66 & 15.9 \\
\hline $25-44$ & 165 & 39.9 \\
\hline $45-64$ & 63 & 15.2 \\
\hline$\geq 65$ & 18 & 4.3 \\
\hline \multicolumn{3}{|l|}{ Religion } \\
\hline Orthodox Christian & 356 & 86.0 \\
\hline Muslim & 33 & 8.0 \\
\hline Protestant & 18 & 4.3 \\
\hline Other & 7 & 1.7 \\
\hline \multicolumn{3}{|l|}{ Marital status } \\
\hline Married & 167 & 40.3 \\
\hline Single & 219 & 52.9 \\
\hline Others & 28 & 6.8 \\
\hline \multicolumn{3}{|l|}{ Educational level } \\
\hline No education & 198 & 47.8 \\
\hline Primary education & 109 & 26.3 \\
\hline Secondary and above & 107 & 25.8 \\
\hline \multicolumn{3}{|l|}{ Monthly income in dollar } \\
\hline$\leq 34.2$ & 98 & 23.7 \\
\hline $34.3-73.4$ & 98 & 23.7 \\
\hline$>73.4$ & 218 & 52.6 \\
\hline \multicolumn{3}{|l|}{ Occupation } \\
\hline Civil servant & 49 & 11.8 \\
\hline Constr. Worker & 6 & 1.4 \\
\hline Driver/assistant & 16 & 3.9 \\
\hline Daily laborers & 47 & 11.4 \\
\hline Farmer & 123 & 29.7 \\
\hline House wives & 25 & 6.0 \\
\hline Student & 82 & 19.8 \\
\hline Trader of any kind & 57 & 13.8 \\
\hline Unemployed & 9 & 2.2 \\
\hline \multicolumn{3}{|l|}{ Residence } \\
\hline Urban & 229 & 55.3 \\
\hline Rural & 185 & 44.7 \\
\hline
\end{tabular}

\section{Prevalence of injury}

The prevalence of injury in emergency departments of the referral hospitals, was found to be $55.6 \%$ with $95 \% \mathrm{CI}$ (50.7-60.4\%). Of which 116 (50.4\%) cases were from the University of Gondar hospital, 59 (25.7 \%) cases from Felege Hiwot hospital and the rest 55 (23.9\%) of cases were from Debre Birhan hospital. Unintentional injuries were the primary cause for $165(71.7 \%)$ of cases. Forty six percent of the unintentional injury was contributed by Road Traffic Injury (RTI). Regarding the mechanism of injury, assault was cause for $86(37.4 \%)$ and RTI for 78 (33.9\%) of patients (Fig. 1).

Concerning the outcome of injury and the type of care given, 99 (43\%) of patients suffered moderate injury that needs skilled treatment such as suturing of wounds and stabilization of fractures. The other 78 (33.9\%) had a severe injury requiring highly specialized skills of medical and surgical management and the rest 53 (23\%) encountered minor superficial injury. Among the injured patients 161 (70\%) were admitted to hospital 66 (28.7\%) patients were treated and discharged.

The injury resulted fracture in 95 (41.3\%) of patients, $68(29.6 \%)$ had cuts. One hundred sixty four (71.3 \%) had got care at different level health institutions prior to their presentation to the emergency department of referral hospitals (Fig. 2).

The higher proportion 106 (46.1\%) of injury occurred on the street and the least proportion 15 (6.5\%) occurred at school and sports area. The mode of transport used by the casualties was varied among the patients; forty five (19.6\%) were coming by walking or carried by people, $132(57.4 \%)$ used a taxi or other private car, while $9(3.9 \%)$ came by police transport 168 and only 44 (19\%) got an ambulance service to reach the referral hospitals.

\section{Factors associated with injury}

In the bivariate analysis the age of respondents, sex, occupation, residence, substance use, educational level and income were identified to be significantly associated with injury. However, only age 20-44 $(\mathrm{AOR}=2.25 ; 95 \% \mathrm{CI}$, 1.06-4.81), sex: male ( $\mathrm{AOR}=2.83$; $95 \% \mathrm{CI}, 1.79-4.47)$, income less than 34.2 USD (AOR $=1.89 ; 95 \% \mathrm{CI}, 1.03-3.45$ ), occupation; daily laborers ( $\mathrm{AOR}=6.27 ; 95 \% \mathrm{CI}, 2.38-16.47$ ) and farmers $(\mathrm{AOR}=2.90 ; 95 \% \mathrm{CI}, 1.31-6.41)$ respectively and substance use $(\mathrm{AOR}=2.16 ; 95 \% \mathrm{CI}, 1.18-3.96)$ were remained significantly associated with injury at the multiple logistic regression analysis (Table 2).

\section{Discussion}

The study found that $55.6 \%$ (at $95 \%$ CI 50.7-60.4\%) of emergency visits were due to injury. The result of this study is much higher than the community based study of Tanzania (4.3\%) [16]. This difference may be due to 


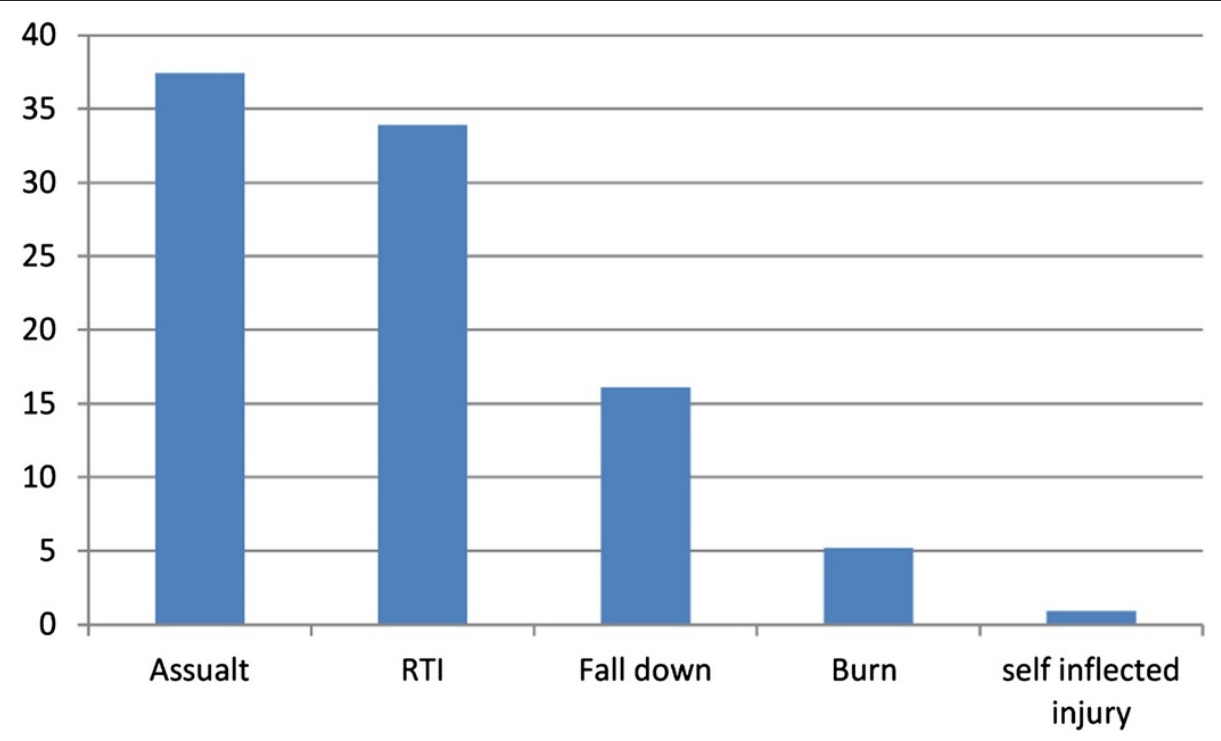

Fig. 1 Mechanism of injury in patients visiting the emergency department of Amhara regional state referral hospitals, $2014(n=230)$

differences in the study setting, since current study conducted in the hospital setting, mainly the emergency departments.

The finding of this paper is approximately twice as reports of hospital based data of Cameroon $27 \%$ [17]. A possible explanation of the difference may be the current study is in the emergency department while the
Cameroon study was a review of ward logs for injury data completeness. The result of this study is slightly lower than studies conducted in Uganda $70.4 \%$ [18]. This may be due to the fact that, the current study was done in regional referral hospitals, while the Uganda's study was done in its capital city (Kampala). The discrepancy may also be explained by difference in student

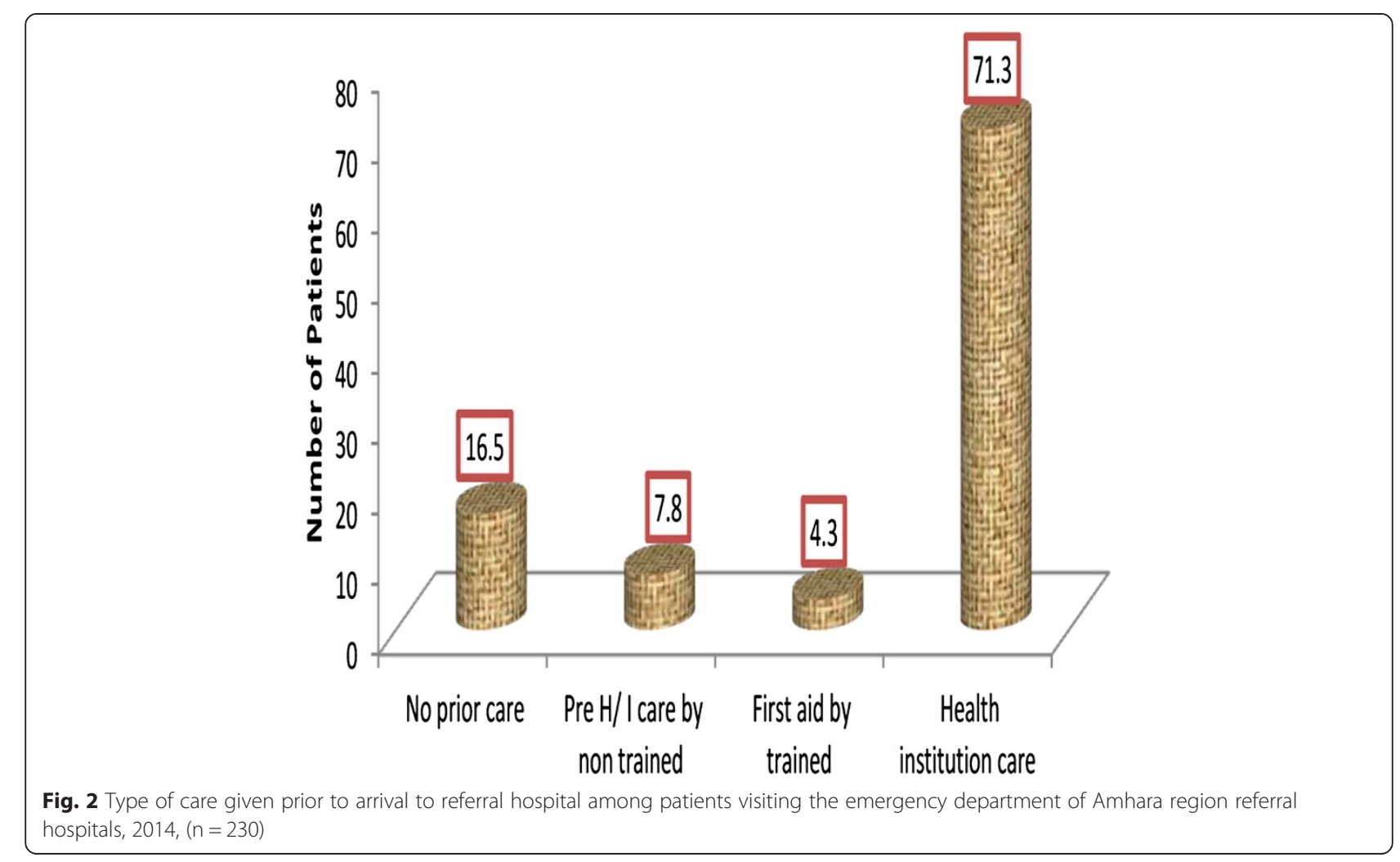


Table 2 Bivariate and multivariate out put on factors affecting prevalence of injury in Amhara regional state referral hospitals, 2014

\begin{tabular}{|c|c|c|c|c|}
\hline Variables & Non injured & Injured & Bi vairate analysis $\mathrm{COR}(\mathrm{Cl})$ & Multivariate analysis AOR (Cl) \\
\hline \multicolumn{5}{|l|}{ Sex } \\
\hline Male & 101 & 177 & $2.7(1.8-4.18)^{*}$ & $2.8(1.79-4.47)^{*}$ \\
\hline Female & 83 & 53 & 1 & 1 \\
\hline \multicolumn{5}{|l|}{ Age } \\
\hline$\leq 19$ & 35 & 67 & $1.8(1.12-3.130)$ & $1.3(.72-2.10)$ \\
\hline $20-44$ & 101 & 130 & $2.7(1.52-5.08)^{*}$ & $2.2(1.06-4.81)^{*}$ \\
\hline$>45$ & 48 & 33 & 1 & 1 \\
\hline \multicolumn{5}{|l|}{ Marital status } \\
\hline Married & 81 & 86 & 1 & \\
\hline Single & 88 & 131 & $1.4(.93-2.10)$ & \\
\hline Others & 15 & 13 & $.81(.36-1.82)$ & \\
\hline \multicolumn{5}{|l|}{ Income (\$) } \\
\hline$\leq 34.2$ & 85 & 141 & $1.84(1.24-2.73)^{*}$ & $1.89(1.03-3.45)^{*}$ \\
\hline$>34.2$ & 99 & 89 & 1 & 1 \\
\hline \multicolumn{5}{|l|}{ Educ. level } \\
\hline Illiterate & 87 & 111 & 1.04(.70-1.53) & \\
\hline Litrate & 97 & 119 & 1 & \\
\hline \multicolumn{5}{|l|}{ Alcohol use } \\
\hline Yes & 21 & 49 & $2.1(1.20-3.65)^{*}$ & $2.16(1.18-3.96)^{*}$ \\
\hline No & 163 & 181 & 1 & 1 \\
\hline \multicolumn{5}{|l|}{ Occupation } \\
\hline Daily labourers & 11 & 36 & $7.42(2.99-18.39)^{*}$ & $6.27(2.38-16.47)^{*}$ \\
\hline Student & 33 & 49 & $3.36(1.58-7.13)$ & $2.19(.84-5.68)$ \\
\hline Farmers & 49 & 74 & $3.42(1.68-6.94)^{*}$ & $2.9(1.31-6.41)^{*}$ \\
\hline Trader & 33 & 24 & 1.64(.73-3.68) & $1.5(.66-3.68)$ \\
\hline Others & 24 & 32 & $3.02(1.35-6.76$ & $2.48(.91-6.77)$ \\
\hline Civil servants & 34 & 15 & 1 & 1 \\
\hline \multicolumn{5}{|l|}{ Residence } \\
\hline Rural & 72 & 113 & $1.5(1.01-2.22)^{*}$ & 1.08(.53-1.10) \\
\hline Urban & 112 & 117 & 1 & 1 \\
\hline \multicolumn{5}{|l|}{ Psych active. } \\
\hline Yes & 11 & 27 & $2.09(1.00-4.34)^{*}$ & $2.14(.97-4.75)$ \\
\hline No & 173 & 203 & 1 & 1 \\
\hline
\end{tabular}

*Significantly associated at $\mathrm{p}$-value $<0.05 .{ }^{\circ}$ Variables included in the multivariate analysis were: age, sex, marital status, income, educational level, alcohol use, occupation, residence, psycho active substance use

population and the data source, since the current paper used primary data. The finding of this work is lower than reports from Addis Ababa, Ethiopia, which is $70.5 \%$ [9]. The difference may be due to the difference in the duration of the study.

However, the current finding is higher than findings of Jimma University specialized Hospital (JUSH) $8.2 \%$ and Tikur Anbessa Specialized referral Hospital (TASRH) which is $32.5 \%[15,19]$. The Possible explanation may be the difference in the study setting. The current study is conducted only in the emergency departments while the JUSH and TASRH studies included all departments in the hospital.

In this study unintentional injuries contribute for more than two third 165 (71.7\%) of the injury cases. This figure is supported by the study conducted in Addis Ababa, which showed $76.4 \%$ of cases were unintentional [20]. Road traffic injury (RTI) is one of the most common injuries contributed to $46 \%$ of unintentional injuries. This may be due to lack of well established pedestrian's road in the region. Furthermore, there is no separate road for domestic animals in the 
region and also most of the main roads are not supported by a traffic light.

The cause of injury was assaulted in $37.4 \%$ cases followed by RTI (33.9 \%). This finding is similar to findings in Jimma University Specialized hospital in which assault contributed to $30.9 \%$ of injury cases followed by RTI $30.3 \%$ [20]. However, it contradicts with findings of Tikur Anbessa in which RTI ranks first $38.3 \%$, followed by striking / hit by a person $31.5 \%$. This may be due to the fact that regional referral hospitals serve for both referral cases and non referral patients. So that, any injury patient of any cause can visit the emergency department. Another explanation may be regional states are less crowded with vehicles than the Addis Ababa city so that RTI can be high in Addis Ababa.

The primary places for the occurrence of injury were street for $46.1 \%$ cases followed by home and home environment (27\%). This is supported by reports made from the state of Qatar, JUSH, and Tikur Anbessa Hospital $[21,22]$. This study showed that $43 \%$ of patients suffered moderate injury that needs skill treatment (eg. Stabilization of fractures, suturing of the wound) followed by severe injury which is $33.9 \%$ and the rest $20.9 \%$ had minor injuries. This finding is similar to findings of JUSH [22] which classified $41.3 \%$ as moderate and $26 \%$ as having a minor superficial injury. However study in Addis Ababa reported moderate injury as $71 \%$ sever as $14.6 \%$.

This study found that, the sex was significantly associated with injury, i.e. Males were 2.8 times more likely to sustain injury. This is supported by the findings of other similar studies $[4,5,20,23]$. This may be explained by the similarity in male travelling risk, emotional and risk taking behavior. Age was also seen to be associated with injury and the odds of injury were 2.3 times more likely in participants' ages between 20-44 years. This is similar to findings of WHO, Quatar, Addis Ababa, JUSH and Tikur Anbessa [5, 20, 21]. Possible explanation may be that this age group is the active working years of life, time for practicing independent life out of parental supervision. In turn, this may predispose them to use substances. This magnifies the possible economic impact of injury as the productive age group of the society is primarily affected.

The study has also indicated that farmers were 2.9 times and daily laborers were 6 times more likely to be injured as compared to civil servants. The result is in line with study in Jimma that reveals more than a quarter $(27.8 \%)$ of injury patients were farmers [22]. This may be due to the fact that minimum 241 or no safety measures are used by farmers as well as the day laborers. Another explanation may be most of the civil servants live relatively stable and less risky life.

The study has also indicated that increased risk of injury with decreased income level. Patients who have a monthly income $<34.2$ USD were 1.89 times more likely to visit the ED because of injury. This is supported with study in Minnesota that states monthly income $<416$ USD increases the risk of injury by 2.85 times [24]. This may be because of their low income level; they may try to find other means of income which may have injury risk, or they may have impaired thought process, stressed and lack concentration in their activity [25].

Substance use was also shown to be another important variable significantly associated with injury. Those patients who had reported to use alcohol were 2.16 times more likely to present for injury. This is almost similar to findings of Minnesota that reported alcohol use increased injury risk by 1.79 times [24]. The observed result is supported by reports of WHO that showed, up to $45 \%$ of injured patients reported consumption of alcohol prior to their injury [26]. Also reviews from Cape Town and Canadian study reported drunkenness (social risk taking) was positively associated with injuries [26, 27].

\section{Limitation of the study}

Since the study was conducted in hospitals, merely in emergency departments of the referral hospitals it cannot be generalized to the population living in the catchment area and prevalence of injury may be overestimated. Furthermore the time of year may also create a selection bias in the results, as injury patterns have been shown to vary seasonally; this could affect other diseases that typically present to the emergency room, limiting the interpretation of the results. In addition, since the study addresses only the human factor of injury the other factors remained untouched.

\section{Conclusion}

The study found that the magnitude of injury is considerably high in Amhara regional, state referral hospitals and also age between 20 to 44, being male, monthly income $<34.2 \$$, being a farmer, being a day laborer, and alcohol use was significantly associated with injury.

\section{Abbreviations}

AOR: Adjusted odds ratio; C I: Confidence interval; CSA: Central statistical agency; D ALYs: Disability adjusted life years; E D: Emergency department; FMoH: Federal ministry of health; JUSH: Jimma university specialized hospital; LMIC: Low and middle income countries; MOH: Ministry of health; RTI: Road traffic injury; SPSS: Statistical package for social sciences; SSA: Sub Saharan Africa; USA: United States of America; WHO: World Health Organization.

\section{Competing interests}

The authors declare that there are no competing interests.

\section{Authors' contributions}

DT carried out the study starting from conception, analysis and interpretation of data and drafting and reviewing of the manuscript. BA participated in data analysis, interpretation and critical review of the manuscript. BT participated in reviewing, data analysis, commenting on and drafting the manuscript. All authors read and approved the final draft of the manuscript. 


\section{Authors' information}

Deberwork is a Lecturer and a nurse practitioner in the Department Nursing, College of Medicine and Health Sciences at University of Gondar, Ethiopia. She has a Bachelor of Science Degree in Nursing, MSc in Surgical Nursing Specialization.

Berihun is Assistant Professor at the department of Biostatistics and Epidemiology, Institute of Public Health, College of Medicine and Health Sciences at University of Gondar, Ethiopia. He has a Bachelor of Science Degree in Nursing, MSc in Adult Health Nursing, Masters of Public Health in Biostatistics and Epidemiology Specialization.

Bewket is Lecturer at the department Nursing, College of Medicine and Health Sciences at University of Gondar, Ethiopia. He has a Bachelor of Science Degree in Nursing, MSc in emergency medicine and critical care nursing Specialization.

\section{Acknowledgements}

The authors would like to forward their deepest gratitude to the University of Gondar for financial support.

\section{Author details}

${ }^{1}$ Department of Nursing, College of Medicine and Health Sciences, University of Gondar, Gondar, Northwest Ethiopia. ${ }^{2}$ Department of Epidemiology and Biostatistics, Institute of Public Health, College of Medicine and Health Sciences, University of Gondar, Gondar, Northwest Ethiopia.

Received: 2 September 2014 Accepted: 6 August 2015

Published online: 25 August 2015

\section{References}

1. World Health Organization: Health status http://www.abs.gov.au/ausstats/ abs@.nsf/Lookup/by\%20Subject/1301.0 2012; 2012.

2. El Tayeb El, Abdalla S, Morkve O, Heuch I, Van den Bergh G. Injuries in Khartoum state, the Sudan: a household survey of incidence and risk factors. International journal of injury control and safety promotion. 2014;21(2):144-53. Epub 2013/05/10.

3. World health organization. The global burden of disease. 2008.

4. World health organization. The magnitude and causes of injury. Injuries and violence the fact sheet. 2004.

5. World health organization. Burden: mortality, morbidity and risk factors. 2008

6. Lu T, Hsiao A, Chang P, Chao Y, Hsu C, Peng H, et al. Counting injury deaths: a comparison of two definitions and two countries. Injury prevention : Journal of the International Society for Child and Adolescent Injury Prevention. 2015;21(1):127-32. Epub 2013/12/19.

7. Swart L, Niekerk A, Seedat M. Paraprofessional home visitation program to prevent childhood unintentional injuries in low-income communities: a cluster randomized controlled trial. Inj Prev. 2008;14(3):164-9.

8. Moshiro C, Heuch I, Astrom A, Setel P, Hemed Y, Kvale G. Injury morbidity in an urban and a rural area in Tanzania: an epidemiological survey. BMC public health. 2005;5:11. Epub 2005/02/01.

9. Tsegaye F, Abdella K, Ahmed E, Tadesse T, Bartolomeos K. Pattern of Fatal Injuries in Addis Ababa, Ethiopia: A One-year Audit. East and Central African Journal of Surgery 2010;15(2):10-7.

10. Awoke T, Assefa G, Berhanu Z. Pattern magnitude and associated factors of injury. University of Gondar: Twenty third annual conference; 2013. p. 32

11. Brindis D, Jane P, Teresa V, Caron M, Rebecca M. The National Initiative to Improve Adolescent Health by the Year 2010. Improving the Health of Adolescents \& Young Adults: A Guide for States and Communities. 2004

12. Osman M, Kebede $Y$, Anberbir S. Magnitude and pattern of injuries in North Gondar Administrative zone, North West Ethiopia. Ethiop Med J. 2003;41:213-20.

13. International Labor Organization. Estimating the Economic Costs of Occupational Injuries and IIInesses in Developing Countries: Essential Information for Decision-Makers. Geneva: European Union, ILO; 2012.

14. CSA. Ethiopian Housing and Population Survey. 2007.

15. Woldemichael K, Berhanu N. Magnitude and pattern of injury in Jimma University specialized hospital, South west ethiopia. Ethiopian journal of health sciences. 2011;21(3):155-65. Epub 2012/03/22

16. Zimmerman K, Mzige AA, Kibatala PL, et al. Road traffic injury incidence and crash characteristics in Dare salaam: A population based study. Accid Anal Prev. 2011;7:204-10
17. Chichom M, Etoundi M, Azabji K, Juillard C, Stevens K. Hospital-based injury data from level III institution in Cameroon: retrospective analysis of the present registration system. Injury. 2013;44(1):139-43. Epub 2011/11/22.

18. Mutto M, Lawoko S, Nansamba C, Ovuga E, Svanstrom L. Unintentional childhood injury patterns, odds, and outcomes in Kampala City: an analysis of surveillance data from the National Pediatric Emergency Unit. Journal of injury \& violence research. 2011;3(1):13-8. Epub 2011/04/13.

19. Tadesse B, Tekilu S, Nega B, Seyoum N. Pattern of Injury and Associated Variables as Seen in the Emergency Department at Tikur Anbessa Specialized Referral Hospital, Addis Ababa, Ethiopia. East Cent Afr J surg. 2014;19(1):73-82

20. Wolde A, Abdella K, Ahmed E, Tsegaye F, Babaniyi O, Kobusingye O, et al. Pattern of Injuries in Addis Ababa, Ethiopia: A One-year Descriptive Study. East and Central African Journal of Surgery. 2008;13(2):14-22

21. Bener A, Abdulrahman YS, Abdelaleem EY, Khalid MK. Trends and characteristics of injuries in the State of Qatar: hospital-based study. Int J Inj Contr Saf Promot. 2012;19(4):368-72.

22. Woldemichael K, Berhanu N. Magnitude and Pattern of Injury in Jimma University Specialized Hospital, South West Ethiopia. Ethiop J Health Sci. 2011;21(3):155-65.

23. Woldemichael K, Tessema F, Sena L., Sofonias G, Abdella K. Community based survey of injury in Jimma zone, North west Ethiopia. Ethiopian journal of health sciences. 2008;17(4):179-88.

24. Prekker ME, James RM, Erik GR, Michelle HB. The prevalence of injury of any type in an urban emergency department population. Lippincott WiliamsandWilkins. 2009;66(6):1688-95.

25. Gemplers. Stress Leads to IIIness and Injury. TailgaTraining Tips Sheet [Internet]. 2009.

26. WHO. Contry profiles African Region. 2004

27. Pickett W, Molcho M, Simpson K, Janssen I, Kuntsche E, Mazur J, et al, Cross national study of injury and social determinants in adolescents. Injury prevention : journal of the International Society for Child and Adolescent Injury Prevention. 2005;11(4):213-8. Epub 2005/08/06.

\section{Submit your next manuscript to BioMed Central and take full advantage of:}

- Convenient online submission

- Thorough peer review

- No space constraints or color figure charges

- Immediate publication on acceptance

- Inclusion in PubMed, CAS, Scopus and Google Scholar

- Research which is freely available for redistribution 